\title{
Usefulness of assessing masked and white-coat hypertension by ambulatory blood pressure monitoring for determining prevalent risk of chronic kidney disease: the Ohasama study
}

\author{
Atsuhiro Kanno ${ }^{1,2}$, Hirohito Metoki ${ }^{1,3}$, Masahiro Kikuya ${ }^{1}$, Hiroyuki Terawaki ${ }^{4}$, Azusa Hara ${ }^{1}$, \\ Takanao Hashimoto ${ }^{1}$, Kei Asayama ${ }^{5}$, Ryusuke Inoue ${ }^{6}$, Yoh Shishido ${ }^{2}$, Masaaki Nakayama ${ }^{4}$, \\ Kazuhito Totsune ${ }^{1}$, Takayoshi Ohkubo ${ }^{5}$ and Yutaka Imai ${ }^{1,5}$
}

Masked hypertension (MHT) is considered to be associated with organ damage, whereas the association of white-coat hypertension (WCHT) with organ damage remains controversial. Using home blood pressure measurements, we have previously reported that MHT is associated with a risk of chronic kidney disease (CKD) compared with sustained normal blood pressure (SNBP), although WCHT was not significantly related to CKD in a general Japanese population. The objective of this study was to examine CKD risk associated with WCHT and MHT as determined by ambulatory blood pressure (ABP) monitoring. Among 1023 residents in the general Japanese population of Ohasama, ABP and casual blood pressure (CBP) levels were recorded and blood and urine samples were collected. CKD was defined as a positive proteinuria and/or estimated glomerular filtration rate $<60 \mathrm{ml} \mathrm{min}^{-1}$ per $1.73 \mathrm{~m}^{2}$. Participants were categorized into four groups using daytime ABP of $140 / 85 \mathrm{~mm} \mathrm{Hg}$ and CBP of $140 / 90 \mathrm{~mm} \mathrm{Hg}$ as cutoff points: SNBP, $60.0 \%$; WCHT, 15.4\%; MHT, 15.0\%; and sustained hypertension (SHT), 9.6\%. Odds ratios (ORs) for prevalence of CKD were calculated using a multiple logistic regression model. Compared with SNBP, risk of CKD was significantly higher in SHT (OR, 2.81; 95\% confidence interval (CI), 1.66-4.75; $P=0.0001)$, MHT (OR, 2.29; 95\% CI, 1.45-3.63; $P=0.0004)$ and WCHT (OR, 1.67; 95\% CI, 1.03-2.71; $P=0.0368)$. CKD was significantly associated with MHT and WCHT on the basis of ABP monitoring compared with SNBP in the general Japanese population.

Hypertension Research (2010) 33, 1192-1198; doi:10.1038/hr.2010.139; published online 12 August 2010

Keywords: ambulatory blood pressure; chronic kidney disease; masked hypertension; white-coat hypertension

\section{INTRODUCTION}

Ambulatory blood pressure (ABP) has recently been the focus of large amounts of research, and the utility and usefulness of this technique have been recognized and established in the diagnosis and management of hypertension. ${ }^{1-3} \mathrm{ABP}$ is also considered as a useful tool for detecting overall blood pressure (BP) load, nighttime BP level and circadian and short-term variations in BP. These parameters contribute to the diagnosis and treatment of hypertension. ${ }^{4-6}$ The measurement of ABP has enabled us to identify a subgroup of individuals with white-coat hypertension (WCHT), showing persistent hypertensive casual BP (CBP) but normal ABP, and a subgroup of individuals with masked hypertension (MHT), showing normal CBP but hypertensive ABP. MHT is reported to be associated strongly with high risk of morbidity and mortality from cardiovascular disease (CVD). ${ }^{7}$ Conversely, controversy remains about whether WCHT is a benign condition $^{8}$ or linked to an increased risk of target-organ damage and CVD. ${ }^{9,10}$

Chronic kidney disease (CKD) is now considered as a major public health issue. The prevalence of end-stage renal disease is increasing in Japan, and is currently more than 2000 per million population. In 2007 , the number of patients with end-stage renal disease on chronic hemodialysis exceeded $275119 .{ }^{11}$ Moreover, a recent study showed that CKD, defined as an estimated glomerular filtration rate (eGFR) of $<60 \mathrm{ml} \mathrm{min}^{-1}$ per $1.73 \mathrm{~m}^{2}$, has been increasing in Japan. Prevalence of stage 3-5 CKD was estimated as 19.1 million among the general Japanese adult population of 103.2 million. ${ }^{12}$ On the other hand,

\footnotetext{
${ }^{1}$ Department of Clinical Pharmacology and Therapeutics, Tohoku University Graduate School of Medicine and Pharmaceutical Sciences, Sendai, Japan; ${ }^{2}$ Midorinosato Clinic, Iwanuma, Japan; ${ }^{3}$ Department of Medical Genetics, Tohoku University Graduate School of Medicine, Sendai, Japan; ${ }^{4}$ Research Division of Dialysis and Chronic Kidney Disease, Tohoku University, Sendai, Japan; ${ }^{5}$ Department of Planning for Drug Development and Clinical Evaluation, Tohoku University Graduate School of Pharmaceutical Sciences, Sendai, Japan and ${ }^{6}$ Medical Informatics, Tohoku University Graduate School of Medicine, Sendai, Japan

Correspondence: Dr Y Imai, Department of Clinical Pharmacology and Therapeutics, Tohoku University Graduate School of Medicine and Pharmaceutical Sciences, 1-1 Seiryo-cho, Aoba-ku, Sendai, 980-8574, Japan.

E-mail: rinsyo@mail.pharm.tohoku.ac.jp
}

Received 8 December 2009; revised 3 June 2010; accepted 20 June 2010; published online 12 August 2010 
prevalence of stage 4-5 CKD was estimated as 200000 after excluding patients on dialysis. Early detection and appropriate intervention for CKD are thus necessary to prevent further increases in the number of patients with end-stage renal disease. Hypertension is a key risk factor for progression of CKD. To prevent progression of CKD, strict $\mathrm{BP}$ control is considered essential. In a recent study, we demonstrated that CKD risk of WCHT based on home BP (HBP) was no different from that of sustained normal blood pressure (SNBP). ${ }^{13}$

Although several clinical studies have reported associations between $\mathrm{ABP}$ and $\mathrm{CKD},{ }^{14,15}$ only limited information is available from the general population. The objective of this study was to examine $\mathrm{CKD}$ risk associated with WCHT and MHT, as determined by $\mathrm{ABP}$ monitoring.

\section{METHODS}

Design

This cross-sectional study is a part of the Ohasama study, a BP measurement project conducted in the rural community of Ohasama in Iwate Prefecture, Japan. Ohasama had a total population of 7496 in 1992. The socioeconomic and demographic characteristics of this region and details of this project have been described previously. ${ }^{16}$ This project was approved by the Institutional Review Board of Tohoku University School of Medicine and by the Department of Health of the Ohasama Town Government.

\section{Study population}

Among the 7496 residents of Ohasama, 3076 were eligible for annual health checkups in 1992. ${ }^{13}$ Of the 2013 residents who participated in checkups from 1992 to 1997, data on serum creatinine levels, dipstick test for spot urine and confounding factors were unavailable for 214 subjects. Of the remaining 1799 individuals, $\mathrm{ABP}$ measurements were recorded in 1073 participants. A total of 27 participants were excluded because of missing data from ABP monitoring, that is, fewer than 14 measurements during the day or fewer than seven measurements during the night based on the guidelines of the European Society of Hypertension. ${ }^{17}$ This study population thus consisted of 1023 individuals, representing $33 \%$ of the total eligible population. All participants provided written, informed consent to participate in the study, which was approved by the Institutional Review Board of Tohoku University School of Medicine.

\section{ABP monitoring}

ABP was monitored using an ABPM 630 (Nippon Colin, Komaki, Japan), a fully automatic device that uses the cuff-oscillometric method to measure BP. The device was preset to measure BP every $30 \mathrm{~min}$. All devices were validated ${ }^{18}$ and satisfied the criteria outlined by the Association for the Advancement of Medical Instrumentation. ${ }^{19}$ Each ABP monitoring device was attached by welltrained public health nurses who visited the participants on a weekday morning and detached the device the next morning. ${ }^{16}$ Participants were asked to report their daily activities, including the times at which they went to bed and awoke. Normal daily activities were allowed and participants were instructed to keep the nondominant arm still and relaxed to the side during measurements. A nondipper was defined as a patient showing a ratio of nighttime to daytime ambulatory systolic BP $>0.9$.

\section{CBP measurement}

CBP was measured twice by nurses or technicians at local medical centers using a semiautomatic BP measuring device (USM-700F; UEDA Electronic Works, Tokyo, Japan) based on the microphone method with subjects in a seated position after resting for $2 \mathrm{~min}$, and the average of the two readings was used in this analysis. The device has been validated previously $y^{20}$ and meets the criteria of the Association for the Advancement of Medical Instrumentation. ${ }^{19}$

\section{Data collection}

Information on smoking status, habitual drinking, use of antihypertensive medications at baseline, as well as history of cardiovascular disease (CVD), diabetes mellitus or hypercholesterolemia, was verified on the basis of the medical charts of the Ohasama Hospital and a questionnaire administered during annual health checkups. History of CVD was defined as disease of the circulatory system, stroke or transient ischemia attack. Subjects treated with lipid-lowering drugs or with levels of serum total cholesterol $\geqslant 220 \mathrm{mg}$ per $100 \mathrm{ml}$ were considered to have hypercholesterolemia. Subjects receiving treatment with antihyperglycemic agents or with fasting serum glucose level $\geqslant 126 \mathrm{mg}$ per $100 \mathrm{ml}$ or casual glucose level $\geqslant 200 \mathrm{mg}$ per $100 \mathrm{ml}$ were defined as having diabetes mellitus.

\section{Measurement of eGFR and proteinuria}

Serum creatinine (Scr) was measured using the Jaffé method. Kidney function was estimated by the calculated glomerular filtration rate using a modified three-variable equation based on insulin clearance for Japanese as follows: eGFR $\left(\mathrm{ml} \mathrm{min}^{-1}\right.$ per $\left.1.73 \mathrm{~m}^{2}\right)=194 \times(\mathrm{Scr} \text { in enzymatic method })^{-1.094} \times$ age $^{-0.287}(\times 0.739$, if female $){ }^{21}$ We used the following equation to convert the level of Scr from the Jaffé method to that for the enzymatic method (Scr in enzymatic method $=\mathrm{Scr}$ in Jaffé method-0.2). After adjustment, mean Scr ( \pm s.d.) was $0.67 \pm 0.16 \mathrm{mg}$ per $100 \mathrm{ml}$. Proteinuria was diagnosed with a dipstick test for spot urine (Urohemabonbix 5G08C; Bayer Medical, Tokyo, Japan). Proteinuria was considered to be present for a dipstick result of $1+$ or more, which corresponds to a urinary protein level $>30 \mathrm{mg}$ per $100 \mathrm{ml}$. CKD was defined as a composite result of eGFR $<60 \mathrm{ml} \mathrm{min}^{-1}$ per $1.73 \mathrm{~m}^{2}$ and/or positive proteinuria.

\section{Diagnostic criteria for hypertension at each measurement}

The criterion for hypertension in CBP was defined as $140 / 90 \mathrm{~mm} \mathrm{Hg}$ on the basis of the cutoff values from several guidelines. ${ }^{17,22}$ With $\mathrm{ABP}$, the results of the International Database on Ambulatory Blood Pressure Monitoring in Relation to Cardiovascular Outcomes (IDACO) study were applied as diagnostic criteria for hypertension as follows: 24-h hypertension, 130/80 $\mathrm{mm} \mathrm{Hg}$; daytime hypertension, $140 / 85 \mathrm{~mm} \mathrm{Hg}$; and nighttime hypertension, $120 / 70 \mathrm{~mm} \mathrm{Hg}^{23}$

In addition, participants were categorized into four groups on the basis of daytime ABP and CBP: sustained hypertension (SHT), with daytime $\mathrm{ABP} \geqslant 140 / 85 \mathrm{~mm} \mathrm{Hg}$ and $\mathrm{CBP} \geqslant 140 / 90 \mathrm{~mm} \mathrm{Hg}$; MHT, with daytime ABP $\geqslant 140 / 85 \mathrm{~mm} \mathrm{Hg}$ and $\mathrm{CBP}<140 / 90 \mathrm{~mm} \mathrm{Hg}$; WCHT, with daytime ABP $<140 / 85 \mathrm{~mm} \mathrm{Hg}$ and $\mathrm{CBP} \geqslant 140 / 90 \mathrm{~mm} \mathrm{Hg}$; or SNBP, with daytime $\mathrm{ABP}<140 / 85 \mathrm{~mm} \mathrm{Hg}$ and $\mathrm{CBP}<140 / 90 \mathrm{~mm} \mathrm{Hg}$.

\section{Statistical analysis}

Continuous variables are expressed as means \pm s.d. Discrete variables are presented as numbers and percentages. Statistical differences in means among groups were analyzed using one-way analysis of variance (ANOVA) or $\chi^{2}$-test as appropriate. A multivariate logistic regression model was used to examine associations between CKD and clinical parameters, and we incorporated the following clinical variables into the model as independent variables: age, gender, current smoking status, current habitual drinking status, body mass index, diabetes mellitus, hypercholesterolemia, history of CVD and use of any antihypertensive medications. To compare the association of different BP indices in $\mathrm{CBP}$ and $\mathrm{ABP}$ with $\mathrm{CKD}$, odds ratios (ORs) and 95\% confidence intervals (CIs) were estimated for a 1-s.d. elevation in each BP index. The likelihood ratio of the $\chi^{2}$-value was used as a measure of improvement in the goodness of fit between models containing each single CBP or ABP index and models containing two BP indices. Data were analyzed using SAS version 9.1 software (SAS Institute, Cary, NC, USA).

\section{RESULTS}

\section{Comparison of characteristics among four groups}

The characteristics of subjects as classified by daytime ABP and CBP into four groups are presented in Table 1 . Of the 1023 study subjects, $216(21.1 \%)$ were receiving antihypertensive medication. Among them, $63.4 \%$ were prescribed with calcium channel blockers, $26.4 \%$ with diuretics, $11.5 \%$ with angiotensin-converting enzyme inhibitors, $2.3 \%$ with $\alpha$-blockers and $5.9 \%$ with other drugs. Compared with 
Table 1 Clinical characteristics in four blood pressure groups

\begin{tabular}{|c|c|c|c|c|c|}
\hline Variable & $S N B P(N=614)$ & WCHT $(\mathrm{N}=158)$ & $M H T(N=153)$ & $S H T(\mathrm{~N}=98)$ & $\mathrm{P}$ (adjusted) \\
\hline Age (year) & $65.6 \pm 8.5$ & $69.0 \pm 8.0^{\dagger}$ & $68.4 \pm 7.2^{\dagger}$ & $68.4 \pm 7.8^{\dagger}$ & $<0.0001$ \\
\hline Gender (\%female) & 76.7 & $63.9^{\dagger}$ & 71.8 & $59.1^{\dagger}$ & 0.0003 \\
\hline $\mathrm{BMI}\left(\mathrm{kg} \mathrm{m}^{-2}\right)$ & $23.0 \pm 2.9$ & $23.5 \pm 3.2$ & $23.5 \pm 3.2$ & $24.1 \pm 2.7^{\dagger}$ & 0.0038 \\
\hline Serum creatinine (mg per $100 \mathrm{ml}$ ) & $0.85 \pm 0.14$ & $0.89 \pm 0.18^{\dagger}$ & $0.87 \pm 0.16$ & $0.92 \pm 0.22^{\dagger}$ & $<0.0001$ \\
\hline Proteinuria (\%) & 3.1 & 7.6 & $8.5^{\dagger}$ & $14.2^{\dagger}$ & $<0.0001$ \\
\hline Estimated GFR ( $\mathrm{ml} \mathrm{min}^{-1}$ per $1.73 \mathrm{~m}^{2}$ ) & $77.9 \pm 16.9$ & $75.3 \pm 17.1$ & $74.6 \pm 16.3$ & $73.3 \pm 17.5$ & 0.0142 \\
\hline Estimated GFR $<60 \mathrm{ml} \mathrm{min}^{-1}$ per $1.73 \mathrm{~m}^{2}(\%)$ & 8.6 & 15.1 & $20.2^{\dagger}$ & $22.4^{\dagger}$ & $<0.0001$ \\
\hline CKD (\%) & 10.9 & 19.6 & 24.8 & 28.5 & $<0.0001$ \\
\hline Current smoker (\%) & 8.6 & 12.6 & 12.4 & 13.2 & NS \\
\hline Current drinker (\%) & 16.9 & 22.1 & 16.3 & $29.5^{\dagger}$ & 0.0139 \\
\hline Diabetes mellitus (\%) & 12.3 & 12.0 & 13.0 & 15.3 & NS \\
\hline Hypercholesterolemia (\%) & 29.4 & 36.7 & 35.2 & 38.7 & NS \\
\hline History of cardiovascular disease (\%) & 3.1 & 7.0 & 7.2 & 6.1 & 0.0450 \\
\hline Antihypertensive therapy (\%) & 12.5 & $27.2^{\dagger}$ & $30.7^{\dagger}$ & $28.5^{\dagger}$ & $<0.0001$ \\
\hline Casual SBP (mm Hg) & $120.9 \pm 11.9$ & $149.6 \pm 10.8^{\dagger}$ & $125.6 \pm 9.4^{\dagger, \S}$ & $150.5 \pm 10.7^{\dagger}$ & $<0.0001$ \\
\hline Casual DBP (mm Hg) & $68.1 \pm 8.7$ & $81.8 \pm 9.8^{\dagger}$ & $69.8 \pm 8.0^{\dagger, \S}$ & $80.1 \pm 10.6^{\dagger}$ & $<0.0001$ \\
\hline $24 \mathrm{~h} \mathrm{SBP}(\mathrm{mm} \mathrm{Hg})$ & $118.5 \pm 9.0$ & $124.4 \pm 7.8^{\dagger}$ & $140.0 \pm 8.6^{\dagger, \S}$ & $140.9 \pm 8.3^{\dagger, \S}$ & $<0.0001$ \\
\hline $24 \mathrm{~h} \mathrm{DBP}(\mathrm{mm} \mathrm{Hg})$ & $69.1 \pm 5.5$ & $71.0 \pm 5.1^{\dagger}$ & $80.5 \pm 5.5^{\dagger, \S}$ & $79.6 \pm 6.0^{\dagger, \S}$ & $<0.0001$ \\
\hline Daytime SBP (mm Hg) & $123.6 \pm 9.5$ & $128.9 \pm 7.5^{\dagger}$ & $147.8 \pm 7.8^{\dagger, \S}$ & $148.9 \pm 7.9^{\dagger, \S}$ & $<0.0001$ \\
\hline Daytime DBP (mm Hg) & $72.8 \pm 6.0$ & $74.6 \pm 5.3^{\dagger}$ & $86.0 \pm 5.3^{\dagger, \S}$ & $85.1 \pm 6.4^{\dagger, \S}$ & $<0.0001$ \\
\hline Nighttime SBP (mm Hg) & $108.8 \pm 11.5$ & $116.0 \pm 12.3^{\dagger}$ & $125.6 \pm 13.8^{\dagger, \S}$ & $127.0 \pm 12.5^{\dagger, \S}$ & $<0.0001$ \\
\hline Nighttime DBP (mm Hg) & $62.0 \pm 6.4$ & $64.4 \pm 6.9^{\dagger}$ & $70.4 \pm 8.0^{\dagger, \S}$ & $70.0 \pm 7.2^{\dagger, \S}$ & $<0.0001$ \\
\hline Nighttime/daytime SBP & $0.88 \pm 0.07$ & $0.90 \pm 0.08^{\dagger}$ & $0.84 \pm 0.08^{\dagger, \S}$ & $0.85 \pm 0.07^{\dagger, \S}$ & $<0.0001$ \\
\hline Nighttime/daytime DBP & $0.85 \pm 0.07$ & $0.86 \pm 0.08$ & $0.81 \pm 0.07^{\dagger, \S}$ & $0.82 \pm 0.06^{\dagger, \S}$ & $<0.0001$ \\
\hline Non-dipper (\%) & 39.0 & 46.2 & $28.1^{\S}$ & $22.4^{\dagger, \S}$ & $<0.0001$ \\
\hline
\end{tabular}

Abbreviations: BMI, body mass index; CVD, cardiovascular disease; DBP, diastolic blood pressure; GFR, glomerular filtration rate; NS, no significance; PP, pulse pressure; SBP, systemic blood pressure; SNBP, sustained normal blood pressure, WCHT, white-coat hypertension.

Values are expressed as percentages or means \pm s.d. adjusted by age, sex and BMI.

$\dagger P<0.05$ vs. SNBP group, $\$ P<0.05$ vs. WCHT group.

SNBP, prevalence of proteinuria was significantly higher in MHT and SHT. ABP levels in MHT were similar to those in SHT. Subjects with MHT and SHT were more likely to be prescribed with antihypertensive drugs and to show cardiovascular complications. Scr was significantly higher in SHT and WCHT than in SNBP. In addition, we performed a stratified analysis between the genders; however, there was no significant difference with regard to the prevalence of positive proteinuria, eGFR $<60 \mathrm{ml} \mathrm{min}^{-1}$ per $1.73 \mathrm{~m}^{2}$ and CKD between them.

\section{Adjusted ORs for CKD among four BP groups}

Adjusted ORs for the presence of proteinuria were significantly higher in SHT, MHT and WCHT groups than in the SNBP group (Figure 1a). Adjusted ORs for the presence of eGFR $<60 \mathrm{ml} \mathrm{min}^{-1}$ per $1.73 \mathrm{~m}^{2}$ in SHT and MHT groups were significantly higher than that in the SNBP group (Figure $1 \mathrm{~b}$ ). In addition, adjusted ORs for the presence of CKD were significantly higher in SHT, MHT and WCHT groups than in the SNBP group (Figure 1c).

Furthermore, there is also a possibility that, using a $140 \mathrm{~mm} \mathrm{Hg}$ threshold for daytime ABP, prevalence of ambulatory hypertension is underestimated. Therefore, we performed a reanalysis with the use of the $135 / 85 \mathrm{~mm} \mathrm{Hg}$ threshold for daytime ABP. As a result, prevalence of WCHT was decreased from 15.4 to $12.0 \%$, whereas that of MHT was increased from 15.0 to $22.4 \%$, respectively. Using $135 / 85 \mathrm{~mm} \mathrm{Hg}$ threshold for daytime ABP, adjusted ORs for the presence of proteinuria in the WCHT group (OR, 3.27; 95\% CI, 1.44-7.40; $P<0.01$ ) and the MHT group (OR, 2.57; 95\% CI, 1.23-5.38; $P=0.01$ ) were significantly higher than that in the SNBP group, which were similar to the results in the case of $140 / 85 \mathrm{~mm} \mathrm{Hg}$ threshold. Regarding the OR for eGFR $<60 \mathrm{ml} \mathrm{min}^{-1}$ per $1.73 \mathrm{~m}^{2}$ or CKD, results similar to those of $140 / 85 \mathrm{~mm} \mathrm{Hg}$ threshold were observed.

When the WCHT group was subdivided into two groups (WCHT-1 (those with lower systolic daytime ABP) and WCHT-2 (those with higher systolic daytime $\mathrm{ABP}$ )) around the median systolic daytime ABP (130.6 $\mathrm{mm} \mathrm{Hg}$ ), CBP was significantly higher in the WCHT-1 and WCHT-2 groups than in the SNBP group (Table 2). Daytime, nighttime and 24-h ABP measurements were significantly higher in the WCHT-2 group than in the SNBP group, although there were no significant differences in ABP values between the WCHT-1 and SNBP groups (Table 2). The systolic ABP in the WCHT-2 group was also significantly higher than that in the WCHT-1 group (Table 2).

The adjusted OR for proteinuria was significantly higher in the WCHT-2 group compared with the SNBP group (OR, 2.73; $P=0.04$ ). 

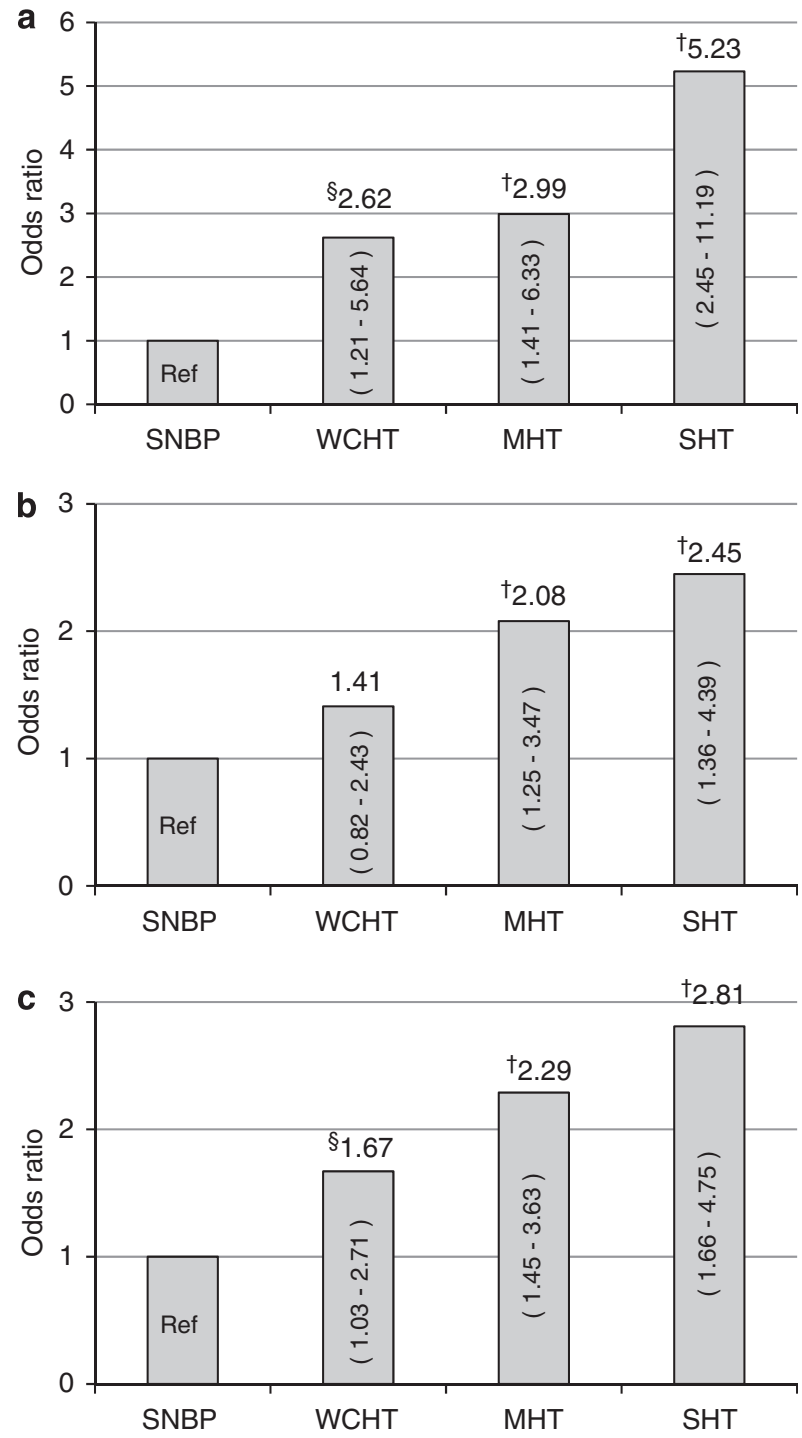

Figure 1 Odds ratios and 95\% confidence intervals for the presence of (a) proteinuria, (b) estimated glomerular filtration rate $<60 \mathrm{ml} \mathrm{min}^{-1}$ per $1.73 \mathrm{~m}^{2}$ and (c) chronic kidney disease (CKD) associated with combinations of groups with and without hypertension in daytime ambulatory blood pressure (ABP) and casual blood pressure (CBP), adjusted for age, gender, body mass index, smoking status, alcohol intake, antihypertensive medication, history of cardiovascular disease, history of diabetes mellitus and hypercholesterolemia. ${ }^{\S} P<0.03$ vs. reference; ${ }^{\dagger} P<0.01$ vs. reference. $\mathrm{MHT}$, masked hypertension; SHT, sustained hypertension; SNBP, sustained normal blood pressure; WCHT, white-coat hypertension.

Corresponding OR in the WCHT-1 group was almost significantly higher than that in the SNBP group (OR, 2.51; $P=0.06$ ) (Figure 2a). Adjusted OR for CKD also tended to be higher in the WCHT-1 (OR, $1.54 ; P=0.19)$ and WCHT-2 groups $(\mathrm{OR}, 1.81 ; P=0.06)$ than in the SNBP group (Figure 2b). On the other hand, when we conducted logistic regression analysis treating the WCHT-1 group as the reference category, adjusted ORs in the WCHT-2 group for the presence of proteinuria $(\mathrm{OR}, 1.09 ; 95 \% \mathrm{CI}, 0.33-3.60 ; P=0.89)$ and $\mathrm{CKD}(\mathrm{OR}$, 1.18 ; $95 \%$ CI, $0.53-2.64 ; P=0.69)$ were almost similar to those in the WCHT-1 group without any significant differences. No significant differences in adjusted ORs of eGFR $<60 \mathrm{ml} \mathrm{min}^{-1}$ per $1.73 \mathrm{~m}^{2}$ and CKD were seen between WCHT and SNBP.
Table 2 Comparison of CBP and ABP in the SNBP and subdivided WCHT groups

\begin{tabular}{lccc}
\hline & $\begin{array}{c}\text { SNBP } \\
(\mathrm{N}=614)\end{array}$ & $\begin{array}{c}\text { WCHT-1 } \\
(\mathrm{N}=79)\end{array}$ & $\begin{array}{c}\text { WCHT-2 } \\
(\mathrm{N}=79)\end{array}$ \\
\hline Systolic CBP (mm Hg) & $121 \pm 12$ & $149 \pm 10^{\dagger}$ & $151 \pm 12^{\dagger}$ \\
Diastolic CBP (mm Hg) & $68 \pm 9$ & $83 \pm 9^{\dagger}$ & $81 \pm 11^{\dagger}$ \\
Systolic daytime ABP (mm Hg) & $124 \pm 10$ & $123 \pm 6$ & $135 \pm 3^{\dagger, \ddagger}$ \\
Diastolic daytime ABP (mm Hg) & $73 \pm 6$ & $72 \pm 5$ & $77 \pm 4^{\dagger}$ \\
Systolic nighttime ABP (mm Hg) & $109 \pm 12$ & $112 \pm 13$ & $120 \pm 10^{\dagger, \ddagger}$ \\
Diastolic nighttime ABP (mm Hg) & $62 \pm 6$ & $63 \pm 8$ & $66 \pm 6^{\dagger}$ \\
Systolic 24h ABP (mm Hg) & $118 \pm 10$ & $119 \pm 7$ & $130 \pm 4^{\dagger, \ddagger}$ \\
Diastolic 24h ABP (mm Hg) & $69 \pm 6$ & $69 \pm 5$ & $73 \pm 4^{\dagger, \ddagger}$ \\
\hline
\end{tabular}

Abbreviations: ABP, ambulatory blood pressure; $C B P$, casual blood pressure; SNBP, sustained normal blood pressure; WCHT, white-coat hypertension.

${ }^{\dagger} P<0.05$ vs. SNBP group $\stackrel{\ddagger}{\ddagger}<0.05$ vs. WCHT- 1 group. Values are expressed as means \pm s.d.

The adjusted OR for CKD was significantly higher in the MHT and SHT groups than in the SNBP group, in spite of antihypertensive treatment (Figure 3). When subjects with and without medication were analyzed separately, similar results were obtained (data not shown).

When nighttime ABP was further added into logistic regression models, the adjusted OR for the presence of proteinuria in the WCHT group remained significantly higher than that in the SNBP group $(P=0.03)$, whereas the adjusted $\mathrm{OR}$ in the MHT group was not significantly different $(P=0.09)$. Similarly, after adjustment of nighttime ABP, the significance for proteinuria of WCHT on the basis of higher daytime systolic ABP disappeared $(P=0.08)$.

Association of $\mathrm{ABP}$ and $\mathrm{CBP}$ as continuous variables with risk of proteinuria, estimated GFR $<60 \mathrm{ml} \mathrm{min}{ }^{-1}$ per $1.73 \mathrm{~m}^{2}$ and CKD For systolic BP, daytime, nighttime and 24-h ABPs were significantly associated with prevalence of proteinuria, eGFR $<60 \mathrm{ml} \mathrm{min}^{-1}$ per $1.73 \mathrm{~m}^{2}$ and CKD, whereas no such associations were observed for systolic CBP in Table 3. For diastolic BP, ABP and CBP were similarly associated with prevalence of proteinuria, eGFR $<60 \mathrm{ml} \mathrm{min}^{-1}$ per $1.73 \mathrm{~m}^{2}$ and CKD in Table 3.

\section{DISCUSSION}

In this study, we demonstrated that MHT, WCHT and SHT were significantly associated with higher risks of proteinuria and CKD compared with SNBP on the basis of ABP monitoring in the general population.

We have already reported that risk of cardiovascular mortality and stroke morbidity is significantly higher in subjects with MHT than in those with SNBP. ${ }^{7}$ We have also previously reported that MHT on the basis of HBP is significantly associated with creatinine clearance $<60 \mathrm{ml} \mathrm{min}^{-1}$ with proteinuria when compared with SNBP in the general population. ${ }^{13}$ Consistent with those findings, this study demonstrated that individuals with MHT on the basis of ABP showed a higher prevalence of proteinuria, eGFR $<60 \mathrm{ml} \mathrm{min}^{-1}$ per $1.73 \mathrm{~m}^{2}$ and CKD.

In this study, we compared the $140 / 85 \mathrm{~mm} \mathrm{Hg}$ threshold with the $135 / 85 \mathrm{~mm} \mathrm{Hg}$ threshold of daytime ABP, which is proposed by the Japanese, American and European hypertension guidelines. As a result, adjusted ORs for proteinuria, eGFR $<60 \mathrm{ml} \mathrm{min}^{-1}$ per $1.73 \mathrm{~m}^{2}$ and CKD showed almost similar results; therefore, it is considered that the difference in threshold of daytime ABP did not have a significant impact on CKD risk. 

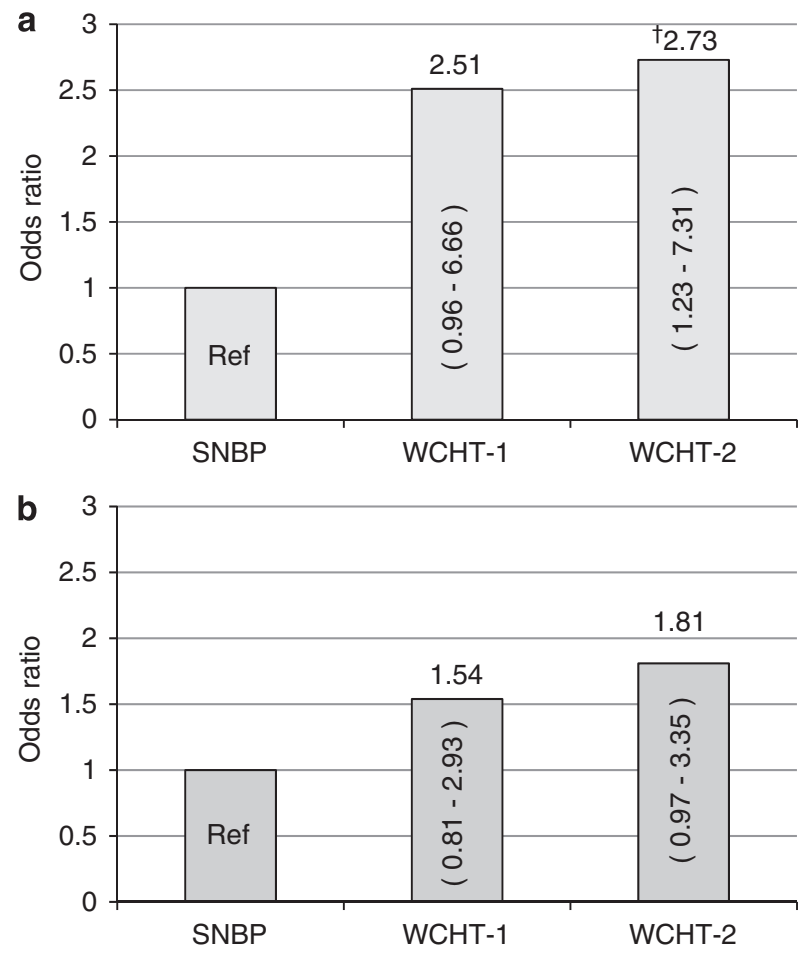

Figure 2 Odds ratios and 95\% confidence intervals for the presence of (a) proteinuria and (b) chronic kidney disease (CKD) associated with the comparison of the sustained normal blood pressure (SNBP) group, adjusted for age, gender, body mass index, smoking status, alcohol intake, history of cardiovascular disease, history of diabetes mellitus and hypercholesterolemia. $\dagger P<0.05$ vs. reference. WCHT, white-coat hypertension.

In the previous study, we reported that treated individuals with optimal BP had a higher stroke risk than untreated ones with optimal $\mathrm{BP}^{24}$ Therefore, in this study, we thought that it is necessary to verify whether there is a residual CKD risk in treated hypertensive patients; hence we added Figure 3. As a result, among SHT, MHT groups, ORs for $\mathrm{CKD}$ in the treated hypertensive population were shown to be higher than in untreated hypertensive patients.

When we included nighttime ABP into the multivariate logistic regression model, MHT was no longer associated with CKD. MHT is considered to be mediated mainly by nondipper and riser status, and thus by nocturnal elevation of BP. ${ }^{25}$ Nocturnal BP may represent a common mechanism related to risk of CKD in subjects with MHT defined by daytime ABP. ${ }^{25}$

WCHT has recently been reported to be associated with a higher risk of coronary artery disease when compared with subjects without WCHT. $^{26}$ In our 8-year follow-up study, WCHT was a significant predictor for the development of HBP hypertension. ${ }^{10}$ In addition, one-third of patients with nondialytic CKD of stage 3-5 reportedly show WCHT. ${ }^{27}$ In this study, WCHT with a relatively higher daytime ABP showed increased risk of proteinuria. This result is different from that of the previous study on the basis of HBP. This might be partly because ABP includes a comprehensive BP information, that is, an average daily BP load, a component of short-term variability of BP, BP in the morning and circadian variation of BP more than HBP. These results indicate that WCHT is not innocent, but is a condition warranting a follow-up. Individuals with WCHT should receive careful long-term follow-up.

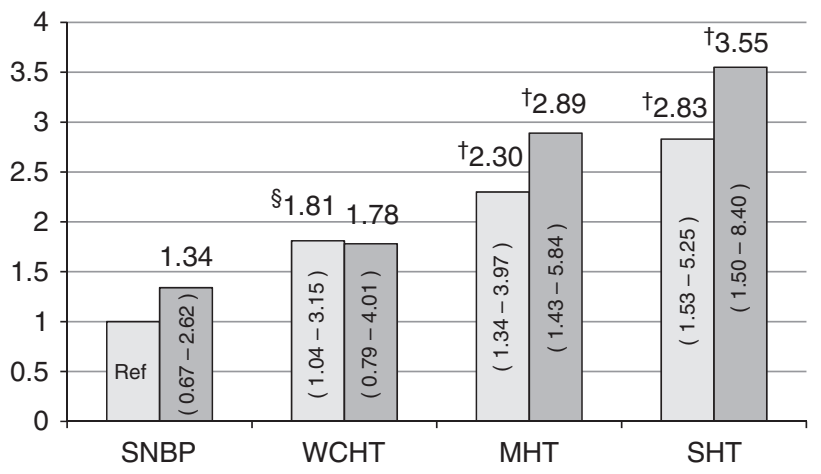

Figure 3 Odds ratios and 95\% confidence intervals for the presence of chronic kidney disease (CKD) in the presence or absence of antihypertensive treatment, adjusted for age, gender, body mass index, smoking status, alcohol intake, history of cardiovascular disease, history of diabetes mellitus and hypercholesterolemia. Antihypertensive medication (-), antihypertensive medication (+). $\$ P<0.05$ vs. reference; $\dagger P<0.01$ vs. reference. MHT, masked hypertension; SHT, sustained hypertension; SNBP, sustained normal blood pressure; WCHT, white-coat hypertension.

In our study, when we subdivided the WCHT group into two groups, the daytime ABP was almost similar between the WCHT group with lower systolic daytime ABP and the SNBP group, whereas adjusted OR for the presence of proteinuria and CKD tended to be higher in the WCHT group with lower systolic daytime ABP than in the SNBP group. On the other hand, even though systolic ABP in the WCHT group with higher systolic daytime ABP was significantly higher than that in the WCHT group with lower systolic daytime ABP, there was no difference in the adjusted ORs for the presence of proteinuria and $\mathrm{CKD}$ between the subdivided WCHT groups. However, CBP was almost similar between these two groups. These results suggest a possibility that the risk in the WCHT group might be largely attributable to the higher CBP rather than to the higher ABP levels.

It has been documented that sympathetic hyperactivity occurs in WCHT. ${ }^{28}$ It is also reported that sympathetic activity is increased in patients with $\mathrm{CKD}^{29}$ In addition, sympathetic nerve activity is shown to be related to kidney injury, especially proteinuria. ${ }^{30}$ However, there is no conclusion about whether sympathetic activity itself leads to kidney injury or whether an increased sympathetic nerve system is derived as a result of development of kidney injury. In the previous study, it was examined that sympathetic blocking agents inhibited albuminuria and glomerulosclerosis without lowering blood pressure $^{31}$. In clinical research, it was shown that sympathetic blocking agents decrease urine albumin excretion in normotensive diabetes patients. ${ }^{32}$ These reports indicate that it is possible that inhibition on sympathetic nerve activity would alleviate kidney injury. These pathophysiological conditions of WCHT and CKD might suggest a relationship between WCHT and kidney injury.

WCHT was significantly related to the prevalence of proteinuria, but this association was less marked for the prevalence of eGFR $<60 \mathrm{ml} \mathrm{min}^{-1}$ per $1.73 \mathrm{~m}^{2}$. It is possible that the underlying mechanisms might thus differ between proteinuria and decreased eGFR. WCHT may reflect a phasic component of BP, whereas SHT and MHT may be associated with tonic load of BP, suggesting that proteinuria may be associated with phasic BP changes, and that decreased eGFR may be related to the tonic load under high BP. Estimated GFR of females is smaller than that of males. The 
Table 3 Comparison of adjusted odds ratio for each condition of renal disorder (per elevation of 1-s.d. of the BP indices)

\begin{tabular}{|c|c|c|c|c|c|c|c|c|c|}
\hline \multirow{2}{*}{$\begin{array}{l}\text { Models } \\
\text { BP variables }\end{array}$} & \multicolumn{3}{|c|}{ Proteinuria } & \multicolumn{3}{|c|}{ eGFR $<60 \mathrm{~m} / \mathrm{min}^{-1}$ per $1.73 \mathrm{~m}^{2}$} & \multicolumn{3}{|c|}{$C K D$} \\
\hline & Odds ratio $(95 \% \mathrm{Cl})$ & P-value & $L R$ & Odds ratio $(95 \% \mathrm{Cl})$ & P-value & $L R$ & Odds ratio $(95 \% \mathrm{Cl})$ & P-value & $L R$ \\
\hline \multicolumn{10}{|l|}{ Systolic BP } \\
\hline \multicolumn{10}{|l|}{ Casual+24 h } \\
\hline Casual & $1.27(0.97-1.69)$ & NS & 2.9 & $1.09(0.89-1.34)$ & NS & 0.7 & $0.98(0.74-2.29)$ & NS & 2.3 \\
\hline $24 \mathrm{~h}$ & $1.66(1.25-2.20)$ & 0.0004 & 12.4 & $1.28(1.04-1.58)$ & 0.0193 & 5.5 & $1.36(1.13-1.64)$ & 0.0011 & 10.7 \\
\hline Casual & $1.30(0.98-1.72)$ & NS & 3.2 & $1.09(0.89-1.34)$ & NS & 0.7 & $1.16(0.97-1.39)$ & NS & 2.5 \\
\hline Daytime & $1.54(1.16-2.04)$ & 0.0030 & 8.8 & $1.29(1.05-1.59)$ & 0.0164 & 5.8 & $1.34(1.11-1.61)$ & 0.0021 & 9.5 \\
\hline \multicolumn{10}{|c|}{ Casual+nighttime } \\
\hline Casual & $1.30(0.98-1.71)$ & NS & 3.4 & $1.12(0.91-1.37)$ & NS & 1.1 & $1.17(0.98-1.41)$ & NS & 3.0 \\
\hline Nighttime & $1.65(1.25-2.18)$ & 0.0005 & 12.3 & $1.19(0.97-1.46)$ & NS & 2.8 & $1.30(1.09-1.57)$ & 0.0042 & 8.2 \\
\hline $24 \mathrm{~h}$ & $1.39(1.06-1.82)$ & 0.0181 & 5.6 & $1.27(1.04-1.56)$ & 0.0223 & 5.2 & $1.37(1.06-1.52)$ & 0.0105 & 6.6 \\
\hline \multicolumn{10}{|c|}{ Casual+daytime } \\
\hline Casual & $1.25(0.95-1.64)$ & NS & 2.4 & $1.25(1.03-1.53)$ & 0.0265 & 4.9 & $1.31(1.10-1.56)$ & 0.0030 & 8.8 \\
\hline Daytime & $1.31(0.99-1.73)$ & NS & 3.6 & $1.28(1.04-1.58)$ & 0.0182 & 5.6 & $1.26(1.05-1.51)$ & 0.0149 & 5.9 \\
\hline \multicolumn{10}{|c|}{ Casual+nighttime } \\
\hline Casual & $1.22(0.93-1.61)$ & NS & 2.0 & $1.26(1.04-1.53)$ & 0.0205 & 5.4 & $1.31(1.10-1.57)$ & 0.0027 & 9.0 \\
\hline Nighttime & $1.41(1.08-1.84)$ & 0.0116 & 6.4 & $1.19(0.97-1.45)$ & NS & 2.8 & $1.24(1.03-1.48)$ & 0.0205 & 5.4 \\
\hline
\end{tabular}

Abbreviations: BP, blood pressure; Cl, confidence interval; CKD, chronic kidney disease; GFR, glomerular filtration rate; LR, likelihood ratio; NS, not significant.

percentage of females in the WCHT group of this study was significantly lower than that of the SNBP group (Table 1). Therefore, we imagine that if the proportion of females in the WCHT group had been similar to that in the SNBP group, the percentage of 'subjects with eGFR $<60$ ' in the WCHT group might have been significantly higher than that in the SNBP group.

This study should be interpreted within the context of its potential limitations. First, the level of CBP and the prevalence of hypertension in CBP are overestimated because of the use of single-visit clinic BP measurements. Second, proteinuria was diagnosed in this study using a semiquantitative dipstick test for spot urine, with results of $\geqslant 30 \mathrm{mg}$ per $100 \mathrm{ml}$ representing a positive finding. This approach does not allow subjects with microalbuminuria and overt proteinuria to be distinguished. Third, serum creatinine was measured using the Jaffé method, and this value was corrected to obtain an equivalent value for the enzymatic method using a modified equation. Finally, this study was cross-sectional in design and thus cannot provide any insights into causal relationships between BP parameters and CKD.

This study demonstrated that WCHT, as well as MHT, is an independent risk factor for prevalence of proteinuria and CKD. In the earlier stage of CKD, evaluation of albuminuria and renal function, as well as therapeutic intervention, may be important to prevent future development and progression of CVD, in addition to the development and progression of CKD. ${ }^{33-35}$ These results thus revealed that CKD is significantly related to MHT and WCHT on the basis of ABP monitoring in the general population. Further prospective studies are needed to clarify the role of $\mathrm{ABP}$ measurements in predicting future occurrence of CKD and associated disorders in the general population.

\section{CONFLICT OF INTEREST}

The authors declare no conflict of interest.

\section{ACKNOWLEDGEMENTS}

This study was supported in part by Grants for Scientific Research (15790293, 16590433, 17790381, 18390192, 18590587, 19590929, 19790423, 20590629, 21390201 and 21591016) from the Ministry of Education, Culture, Sports, Science, and Technology, Japan; by Grant-in-Aid (H17-Kenkou-007, H18Junkankitou(Seishuu)-Ippan-012, and H20-Junkankitou(Seishuu)-Ippan-009, 013) from the Ministry of Health, Labor and Welfare, Health and Labor Sciences Research Grants, Japan; by Grant-in-Aid for Japan Society for the Promotion of Science (JSPS) fellows (16. 54041, 18.54042, 19.7152, 20.7198, 20.7477 and 20.54043); by Health Science Research Grants and Medical Technology Evaluation Research Grants from the Ministry of Health, Labor and Welfare, Japan; by the Japan Atherosclerosis Prevention Fund; the Uehara Memorial Foundation; the Takeda Medical Research Foundation; by National Cardiovascular Research Grants; and by Biomedical Innovation Grants.

1 Pickering TG, Hall JE, Appel LJ, Falkner BE, Graves J, Hill MN, Jones DW, Kurtz T, Sheps SG, Roccella EJ. Recommendations for blood pressure measurement in humans and experimental animals: Part 1: blood pressure measurement in humans: a statement for professionals from the Subcommittee of Professional and Public Education of the American Heart Association Council on High Blood Pressure Research. Circulation 2005; 111: 697-716.

2 Pickering T. Recommendations for the use of home (self) and ambulatory blood pressure monitoring. Am J Hypertens 1996; 9: 1-11.

3 O'Brien E, Asmar R, Beilin L, Imai Y, Mallion JM, Mancia G, Mengden T, Myers M, Padfield P, Palatini P, Parati G, Pickering T, Redon J, Staessen J, Stergiou G, Verdecchia $P$. European Society of Hypertension recommendations for conventional, ambulatory and home blood pressure measurement. J Hypertens 2003; 21: 821-848. 
4 Madin K, Iqbal P. Twenty four hour ambulatory blood pressure monitoring: a new tool for determining cardiovascular prognosis. Postgrad Med J 2006; 82: 548-551.

5 Smith DH, Dubiel R, Jones M. Use of 24-h ambulatory blood pressure monitoring to assess antihypertensive efficacy: a comparison of olmesartan medoxomil, losartan potassium, valsartan, and irbesartan. Am J Cardiovasc Drugs 2005; 5: 41-50.

6 Stenehjem AE, Os I. Reproducibility of blood pressure variability, white-coat effect and dipping pattern in untreated, uncomplicated and newly diagnosed essential hypertension. Blood Press 2004; 13: 214-224.

7 Ohkubo T, Kikuya M, Metoki H, Asayama K, Obara T, Hashimoto J, Totsune K, Hoshi H, Satoh H, Imai Y. Prognosis of 'masked' hypertension and 'white-coat' hypertension detected by 24-h ambulatory blood pressure monitoring 10-year follow-up form the Ohasama study. J Am Coll Cardiol 2005; 46: 508-515.

8 Khattar RS, Senior R, Lahiri A. Cardiovascular outcome in white-coat versus sustaind mild hypertension: a 10-year follow-up study. Circulation 1998; 98: 1892-1897.

9 Verdecchia P, Reboldi GP, Angeli F, Schillaci G, Schwartz JE, Pickering TG, Imai Y, Ohkubo T, Kario K. Short- and long-term incidence of stroke in white-coat hypertension. Hypertension 2005; 45: 203-208.

10 Ugajin T, Hozawa A, Ohkubo T, Asayama K, Kikuya M, Obara T, Metoki H, Hoshi H, Hashimoto J, Totsune K, Satoh H, Tsuji I, Imai Y. White-coat hypertension as a risk factor for the development of home hypertension: the Ohasama study. Arch Intern Med 2005; 165: 1541-1546.

11 Japanese Society of Dialysis Therapy. An overview of regular dialysis treatment in Japan as of Dec 31, 2007. 2008. http://docs.jsdt.or.jp/overview/.

12 Imai E, Horio M, Iseki K, Yamagata K, Watanabe T, Hara S, Ura N, Kiyohara Y, Hirakata H, Moriyama T, Ando Y, Nitta K, Inaguma D, Narita I, Iso H, Wakai K, Yasuda Y, Tsukamoto $Y$, Ito S, Makino H, Hishida A, Matsuo S. Prevalence of chronic kidney disease (CKD) in Japanese population predicted by MDRD equation modified by a Japanese coefficient. Clin Exp Nephrol 2007; 11: 156-163.

13 Terawaki H, Metoki H, Nakayama M, Ohkubo T, Kikuya M, Asayama K, Inoue R, Hoshi $\mathrm{H}$, Ito S, Imai Y. Masked hypertension determined by self-measured blood pressure at home and chronic kidney disease in the Japanese general population: the Ohasama study. Hypertens Res 2008; 31: 2129-2135.

14 Agarwal R, Andersen MJ. Blood pressure recordings within and outside the clinic and cardiovascular events in chronic kidney disease. Am J Nephrol 2006; 26: 503-510.

15 Agarwal R, Andersen MJ. Prognostic importance of ambulatory blood pressure recordings in patients with chronic kidney disease. Kidney Int 2006; 69: 1175-1180.

16 Imai Y, Nagai K, Sakuma M, Sakuma H, Nakatsuka H, Satoh H, Minami N, Munakata M, Hashimoto J, Yamagishi T, Watanabe N, Yabe T, Nishiyama A, Abe K. Ambulatory blood pressure of adults in Ohasama, Japan. Hypertension 1993; 22: 900-912.

17 O'Brien E, Asmar R, Beilin L, Imai Y, Mallion JM, Mancia G, Mengden T, Myers M, Padfield P, Palatini P, Parati G, Pickering T, Redon J, Staessen J, Stergiou G, Verdecchia P, European Society of Hypertension Working Group on Blood Pressure Monitoring. European Society of Hypertension recommendations for conventional, ambulatory and home blood pressure measurement. J Hypertens 2003; 21: 821-848.

18 Imai Y, Abe K, Sasaki S, Minami N, Munakata M, Sekino H, Nihei M, Yoshinaga K. Determination of clinical accuracy and nocturnal blood pressure pattern by new portable devices for monitoring indirect ambulatory blood pressure. Am J Hypertens 1990; 3: 293-301.

19 Association for the Advancement of Medical Instrumentation. American National Standard for Electronic or Automated Sphygmomanometers. Association for the Advancement of Medical Instrumentation: Washington, DC, 1987.

20 Imai Y, Abe K, Sasaki S, Minami N, Munakata M, Sakuma H, Hashimoto J, Sekino H, Imai K, Yoshinaga K. Clinical evaluation of semiautomatic and automatic devices for home blood pressure measurement: comparison between cuff-oscillometric and microphone methods. J Hypertens 1989; 7: 983-990.

21 Matsuo S, Imai E, Horio M, Yasuda Y, Tomita K, Nitta K, Yamagata K, Tomino Y, Yokoyama $\mathrm{H}$, Hishida A, Collaborators developing the Japanese equation for estimated GFR. Revised equations for estimated GFR from serum creatinine in Japan. Am J Kidney Dis 2009; 53: 982-992.
22 Chobanian AV, Bakris GL, Black HR, Cushman WC, Green LA, Izzo Jr JL, Jones DW, Materson BJ, Oparil S, Wright Jr JT, Roccella EJ, National Heart, Lung, and Blood Institute Joint National Committee on Prevention, Detection, Evaluation, and Treatment of High Blood Pressure; National High Blood Pressure Education Program Coordinating Committee. The Seventh Report of the Joint National Committee on Prevention, Detection, Evaluation, and Treatment of High Blood Pressure: the JNC 7 report. JAMA 2003; 289: 2560-2572.

23 Kikuya M, Hansen TW, Thijs L, Björklund-Bodegård K, Kuznetsova T, Ohkubo T, Richart T, Torp-Pedersen C, Lind L, Ibsen H, Imai Y, Staessen JA, IDACO investigators. Diagnostic thresholds for ambulatory blood pressure monitoring based on 10-year cardiovascular risk. Circulation 2007; 115: 2145-2152.

24 Asayama K, Ohkubo T, Yoshida S, Suzuki K, Metoki H, Harada A, Murakami Y, Ohashi Y, Ueshima H, Imai Y, Japan Arteriosclerosis Longitudinal Study (JALS) group. Stroke risk and antihypertensive drug treatment in the general population: the Japan arteriosclerosis longitudinal study. J Hypertens 2009; 27: 357-364.

25 Ogihara T, Kikuchi K, Matsuoka H, Fujita T, Higaki J, Horiuchi M, Imai Y, Imaizumi T, Ito S, Iwao H, Kario K, Kawano Y, Kim-Mitsuyama S, Kimura G, Matsubara H, Matsuura H, Naruse M, Saito I, Shimada K, Shimamoto K, Suzuki H, Takishita S, Tanahashi N, Tsuchihashi T, Uchiyama M, Ueda S, Ueshima H, Umemura S, Ishimitsu T, Rakugi H, Japanese Society of Hypertension Committee. The Japanese Society of Hypertension Guidelines for the Management of Hypertension (JSH 2009). Hypertens Res 2009; 32 : 3-107.

26 Kostandonis D, Papadopoulos V, Toumanidis S, Papamichael C, Kanakakis I, Zakopoulos N. Topography and severity of coronary artery disease in white-coat hypertension. Eur J Intern Med 2008; 19: 280-284.

27 Minutolo R, Borrelli S, Scigliano R, Bellizzi V, Chiodini P, Cianciaruso B, Nappi F, Zamboli P, Conte G, De Nicola L. Prevalence and clinical correlates of white coat hypertension in chronic kidney disease. Nephrol Dial Transplant 2007; 22 : 2217-2223.

28 Smith PA, Graham LN, Mackintosh AF, Stoker JB, Mary DA. Relationship between central sympathetic activity and stages of human hypertension. Am J Hypertens 2004; 17: 217-222.

29 Neumann J, Ligtenberg G, Klein IH, Boer P, Oey PL, Koomans HA, Blankestijn PJ. Sympathetic hyperactivity in hypertensive chronic kidney disease patients is reduced during standard treatment. Hypertension 2007; 49: 506-510.

30 Mena-Martín FJ, Martín-Escudero JC, Simal-Blanco F, Carretero-Ares JL, Arzúa-Mouronte D, Castrodeza Sanz JJ, Hortega Study Investigators. Influence of sympathetic activity on blood pressure and vascular damage evaluated by means of urinary albumin excretion. J Clin Hypertens 2006; 8: 619-624.

31 Amann K, Rump LC, Simonaviciene A, Oberhauser V, Wessels S, Orth SR, Gross ML, Koch A, Bielenberg GW, Van Kats JP, Ehmke H, Mall G, Ritz E. Effects of low dose sympathetic inhibition on glomerulosclerosis and albuminuria in subtotally nephrectomized rats. J Am Soc Nephrol 2000; 11: 1469-1478.

32 Strojek K, Grzeszczak W, Górska J, Leschinger MI, Ritz E. Lowering of microalbuminuria in diabetic patients by a sympathicoplegic agent: novel approach to prevent progression of azelnidipine with angiotensin receptor blockers in patients with diabetic nephropathy. J Am Soc Nephrol 2001; 12: 602-605.

33 Hillege HL, Fidler V, Diercks GF, van Gilst WH, de Zeeuw D, van Veldhuisen DJ, Gans RO, Janssen WM, Grobbee DE, de Jong PE, Prevention of Renal and Vascular End Stage Disease (PREVEND) Study Group. Urinary albumin excretion predicts cardiovascular and noncardiovascular mortality in general population. Circulation 2002: 106: 1777-1782.

34 Chertow GM, Fan D, McCulloch CE, Hsu CY. Chronic kidney disease and the risks of death, cardiovascular events, and hospitalization. N Engl J Med 2004; 351: 1296-1305.

35 Brantsma AH, Bakker SJ, Hillege HL, de Zeeuw D, de Jong PE, Gansevoort RT, PREVEND Study Group. Cardiovascular and renal outcome in subjects with K/DOQI stage 1-3 chronic kidney disease: the importance of urinary albumin excretion. Nephrol Dial Transplant 2008; 23: 3851-3858. 